\title{
Pien Tze Huang inhibits the proliferation of human colon carcinoma cells by arresting G1/S cell cycle progression
}

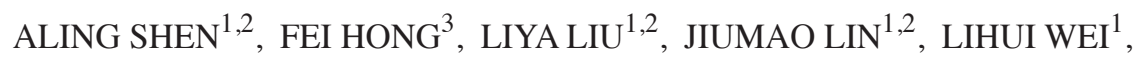 \\ QIAOYAN CAI ${ }^{1,2}$, ZHENFENG HONG ${ }^{1}$ and JUN PENG ${ }^{1,3}$ \\ ${ }^{1}$ Academy of Integrative Medicine; ${ }^{2}$ Fujian Key Laboratory of Integrative Medicine on Geriatrics, \\ Fujian University of Traditional Chinese Medicine, Fuzhou, Fujian 350122; ${ }^{3}$ Postdoctor Workstation, \\ Zhangzhou Pien Tze Huang Pharmaceutical Co., Ltd., Shangjie, Zhangzhou, Fujian 363000, P.R. China
}

Received June 12, 2012; Accepted July 16, 2012

DOI: $10.3892 / \mathrm{ol} .2012 .811$

\begin{abstract}
Pien Tze Huang (PZH), a well-known traditional Chinese formula prescribed 450 years ago in the Ming Dynasty, has been used in China and Southeast Asia for centuries as a folk remedy for various types of cancer, including colorectal cancer (CRC). Recently, we reported that PZH is capable of inhibiting colon cancer growth both in vivo and in vitro via the promotion of apoptosis and inhibition of tumor angiogenesis. To elucidate the mechanism of the tumoricidal activity of PZH, its effect on the proliferation of human colon carcinoma Caco-2 cells was evaluated and the underlying molecular mechanism was investigated. Results showed that PZH inhibited Caco-2 cell viability and survival in a dose- and/or time-dependent manner. In addition, PZH treatment was found to block the G1/S cell cycle progression. Moreover, PZH suppressed the mRNA and protein expression of pro-proliferative Cyclin D1 and CDK4. Findings of the present study suggest that inhibition of cell proliferation via the G1/S cell cycle arrest is a potential mechanism by which PZH can be effective in the treatment of cancer.
\end{abstract}

\section{Introduction}

Colorectal cancer (CRC) is the second most common cause of cancer-related mortality in Western societies (1). Despite recent advances in CRC treatment, 5-fluorouracil (5-FU)-based regimens continue to be the international standard chemotherapy for patients with advanced CRC (2). However, drug resistance profoundly limits the effectiveness of current CRC cancer

Correspondence to: Dr Jun Peng, Academy of Integrative Medicine, 1 Huatuo Road, Minhou Shangjie, Fuzhou, Fujian 350122, P.R. China E-mail: pjunlab@hotmail.com

Abbreviations: CRC, colorectal cancer; PZH, Pien Tze Huang; TCM, traditional Chinese medicine; MTT, 3-(4, 5-dimethylthiazol2-yl)-2,5-diphenyltetrazolium bromide

Key words: Pien Tze Huang, traditional Chinese medicine, colorectal cancer, proliferation, cell cycle chemotherapies (3). Moreover, application of 5-FU-based regimens is often coupled with serious toxicity and side-effects such as anemia, leucopenia, thrombocytopenia and peripheral neuropathy $(4,5)$. Therefore, it is essential to develop safer agents for the chemotherapeutic treatment of CRC. Traditional Chinese medicine (TCM), which has relatively few side-effects, plays an important role in primary health care in China and has recently been recognized by Western countries as a key source for revealing novel lead molecules for modern drug discovery. Clinical practice has also shown that many traditional Chinese medicines possess antitumor activities, which provide insight into new therapeutic strategies for cancer treatment (6-14).

Cancer cells are characterized by an uncontrolled increase in cell proliferation (15). Eukaryotic cell proliferation is primarily regulated by the cell cycle. G1/S transition is one of the two main checkpoints of the cell cycle (16), which is responsible for initiation and completion of DNA replication. G1/S progression is strongly regulated by Cyclin D1, which exerts its function by forming an active complex with its major catalytic partners, such as CDK4 (17). An unchecked or hyperactivated Cyclin D1/CDK4 complex often leads to uncontrolled cell division and malignancy (18-21). Therefore, inhibiting excessive proliferation of tumor cells by blocking Cyclin D1/CDK4-mediated G1/S progression is one of the key approaches for the development of anticancer drugs.

Pien Tze Huang (PZH) is a well-known traditional Chinese formula that was first prescribed 450 years ago in the Ming Dynasty, with properties of heat-clearing and detoxification (22). In the TCM system, accumulation of toxic dampness and heat is a major pathogenic factor of cancer, therefore clearing heat and detoxification is a principle of anticancer treatment. For this reason, PZH has been used in China and Southeast Asia for centuries as a folk remedy for various types of cancer. Modern pharmacological studies have proposed that PZH exhibits therapeutic effects in clinical trials of tumors, such as hepatocellular carcinoma and colon cancer $(23,24)$. In addition, in experimental animals PZH inhibits the growth of Ehrlich-Ascites tumor, gastric carcinoma, and hepatoma (25). Moreover, we recently reported that PZH is able to inhibit colon cancer growth both in vivo and in vitro via the promotion of apoptosis and inhibition of tumor angiogenesis (26-28). To elucidate the mechanism of the tumoricidal activity of PZH, 
we evaluated its effect on the proliferation of the human colon carcinoma cell line Caco- 2 and investigated the underlying molecular mechanism.

\section{Materials and methods}

Materials and reagents. RPMI-1640, fetal bovine serum (FBS), penicillin-streptomycin, Trypsin-EDTA, and TRIzol reagent were purchased from Invitrogen (Carlsbad, CA, USA). SuperScript II reverse transcriptase was obtained from Promega (Madison, WI, USA). Cyclin D1, CDK4 and $\beta$-actin antibodies, and horseradish peroxidase (HRP)-conjugated secondary antibodies were purchased from Cell Signaling (Beverly, MA, USA). Any other chemicals, unless otherwise stated, were obtained from Sigma-Aldrich (St. Louis, MO, USA).

Preparation of $\mathrm{PZH}$. PZH was obtained from and authenticated by the sole manufacturer Zhangzhou Pien Tze Huang Pharmaceutical Co., Ltd., China (Chinese FDA approval no. Z35020242). Stock solution of PZH was prepared immediately prior to use by dissolving the PZH powder in phosphatebuffered saline (PBS) to a concentration of $20 \mathrm{mg} / \mathrm{ml}$. The working concentrations of PZH were obtained by diluting the stock solution in the culture medium.

Cell culture. Human colon carcinoma Caco-2 cells were obtained from the American Type Culture Collection (ATCC, Manassas, VA, USA). Caco-2 cells were grown in RPMI-1640 containing $10 \%(\mathrm{v} / \mathrm{v}) \mathrm{FBS}$, and $100 \mathrm{U} / \mathrm{ml}$ penicillin and $100 \mu \mathrm{g} /$ $\mathrm{ml}$ streptomycin. Cells were cultured at $37^{\circ} \mathrm{C}$, in a $5 \% \mathrm{CO}_{2}$ humidified environment.

Assessment of cell viability. Cell viability was assessed by MTT colorimetric assay. Caco-2 cells were seeded into 96 -well plates at a density of $5 \times 10^{3}$ cells/well in $0.1 \mathrm{ml}$ medium. The cells were treated with various concentrations of PZH for different periods of time. At the end of the treatment, $100 \mu 1 \mathrm{MTT}(0.5 \mathrm{mg} / \mathrm{ml}$ in PBS$)$ were added to each well, and the samples were incubated for an additional $4 \mathrm{~h}$ at $37^{\circ} \mathrm{C}$. The purple-blue MTT formazan precipitate was dissolved in $100 \mu \mathrm{l}$ DMSO. The absorbance was measured at $570 \mathrm{~nm}$ using an ELISA reader (BioTek, Model ELX800, USA).

Colony formation. Caco-2 cells were seeded into 6-well plates at a density of $1 \times 10^{5}$ cells/well in $2 \mathrm{ml}$ medium. After treatment with various concentrations of PZH for $24 \mathrm{~h}$, the cells were collected and diluted in fresh medium in the absence of PZH and then reseeded into 6-well plates at a density of $1 \times 10^{3}$ cells/well. Following incubation for 8 days in a $37^{\circ} \mathrm{C}$ humidified incubator with $5 \% \mathrm{CO}_{2}$, the formed colonies were fixed with $10 \%$ formaldehyde, stained with $0.01 \%$ crystal violet and counted. Cell survival was calculated by normalizing the survival of the control cells as $100 \%$.

Cell cycle analysis. The cell cycle analysis was carried out by flow cytometry using a fluorescence-activated cell sorting (FACS) Calibur (Becton-Dickinson, San Jose, CA, USA) and propidium iodide (PI) staining. Subsequent to treatment with various concentrations of PZH for $24 \mathrm{~h}, \mathrm{Caco}-2$ cells were collected and adjusted to a concentration of $1 \times 10^{6} \mathrm{cells} / \mathrm{ml}$, and fixed in $70 \%$ ethanol at $4^{\circ} \mathrm{C}$ overnight. The fixed cells were washed twice with cold PBS, and then incubated for $30 \mathrm{~min}$ with RNase $(8 \mu \mathrm{g} / \mathrm{ml})$ and PI $(10 \mu \mathrm{g} / \mathrm{ml})$. The fluorescent signal was detected through the FL2 channel and the proportion of DNA in different phases was analyzed using ModfitLT version 3.0 (Verity Software House, Topsham).

RT-PCR analysis. Caco-2 cells were seeded into 6-well plates at a density of $1 \times 10^{5}$ cells/well in $2 \mathrm{ml}$ medium and treated with various concentrations of PZH for $24 \mathrm{~h}$. Total RNA was isolated with TRIzol reagent. Oligo(dT)-primed RNA $(1 \mu \mathrm{g})$ was reverse-transcribed with SuperScript II reverse transcriptase (Promega) according to the manufacturer's instructions. The obtained cDNA was used to determine the mRNA amount of Cyclin D1 and CDK4 by PCR. GAPDH was used as an internal control. The primer sequences used for the amplification of Cyclin D1, CDK4 and GAPDH transcripts were: Cyclin D1, forward: 5'-TGG ATG CTG GAG GTC TGC GAG GAA -3' and reverse: 5'-GGC TTC GAT CTG CTC CTG GCA GGC-3'; CDK4, forward: 5'-CAT GTA GAC CAG GAC CTA AGC-3' and reverse: 5'-AAC TGG CGC ATC AGA TCC TAG-3'; GAPDH, forward: 5'-CG ACC ACT TTG TCA AGC TCA-3' and reverse: 5'-AG GGG TCT ACA TGG CAA CTG-3'. Samples were analyzed by gel electrophoresis (1.5\% agarose). The DNA bands were examined using a Gel Documentation System (BioRad, Model Gel Doc 2000, USA).

Western blotting. Caco- 2 cells $\left(2.5 \times 10^{5}\right.$ cells/well $)$ were seeded into $25 \mathrm{~cm}^{2}$ flasks in $5 \mathrm{ml}$ medium. Cells were treated with various concentrations of PZH for $24 \mathrm{~h}$ and then lysed with mammalian cell lysis buffer containing protease and phosphatase inhibitor cocktails. The lysates were resolved in $12 \%$ SDS-PAGE gels and electroblotted. The PVDF membranes were blocked with $5 \%$ skimmed milk and probed with primary antibodies against CyclinD1, CDK4 and $\beta$-actin $(1: 1,000)$ overnight at $4^{\circ} \mathrm{C}$ and then with appropriate HRP-conjugated secondary antibody followed by enhanced chemiluminescence detection.

Statistical analysis. Data were analyzed using the SPSS package for Windows (Version 11.5). Statistical analysis of the data was performed using the Student's t-test and one-way ANOVA. Differences with $\mathrm{P}<0.05$ were considered statistically significant.

\section{Results}

PZH inhibits the proliferation of Caco-2 cells. The viability of Caco-2 cells was determined by MTT assay to compare the relative number of cells in PZH-treated monolayers to untreated controls. As shown in Fig. 1A, treatment with $0.25-1 \mathrm{mg} / \mathrm{ml}$ of PZH for $24 \mathrm{~h}$ dose-dependently reduced cell viability by $11-35 \%$ compared to the untreated control cells $(\mathrm{P}<0.05)$. We also evaluated the effect of $1 \mathrm{mg} / \mathrm{ml}$ of $\mathrm{PZH}$ on cell viability with incubation for different periods of time. As shown in Fig. 1B, PZH treatment led to a gradual decrease in cell viability with the increase of exposure time. To verify these results, we examined the effect of PZH on Caco-2 cell survival using a colony formation assay. As shown in Fig. 2A and B, PZH treatment dose-dependently reduced the cell survival rate 
A

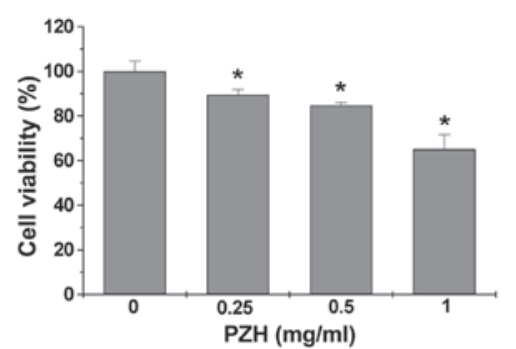

B

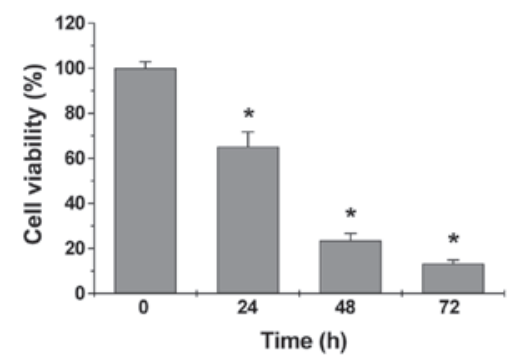

Figure 1. Effect of PZH on Caco-2 cell viability. (A) Caco-2 cells were treated with the indicated concentrations of PZH for $24 \mathrm{~h}$. (B) Cells were treated with $1 \mathrm{mg} / \mathrm{ml}$ of PZH for the indicated time periods. Cell viability was determined by the MTT assay. The data were normalized to the viability of control cells. Data are averages with SD (error bars) from at least three independent experiments. ${ }^{*} \mathrm{P}<0.05$ vs. control cells.

$\mathbf{A}$

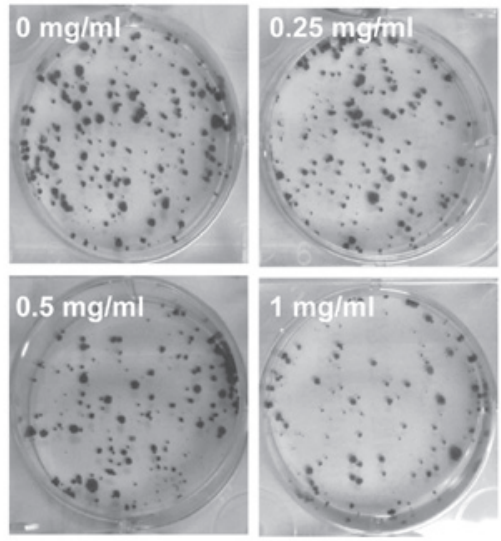

B

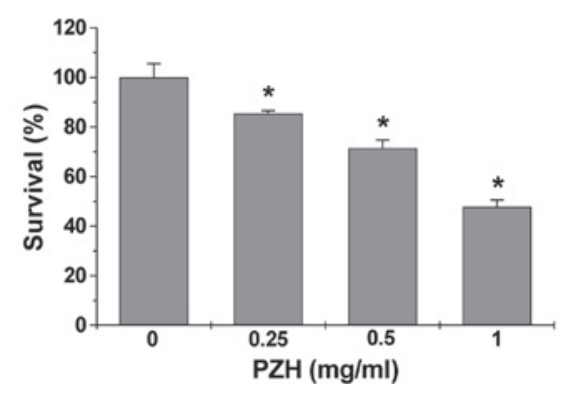

Figure 2. Effect of PZH on Caco-2 cell survival. (A) Cells were treated with the indicated concentrations of PZH for $24 \mathrm{~h}$. Cell survival was determined by colony formation analysis. Images are representative of three independent experiments. (B) Quantification of colony formation analysis. The data were normalized to the survival of control cells and are shown as averages with SD (error bars) from at least three independent experiments. " $\mathrm{P}<0.05$ vs. control cells.

by $15-52 \%$ compared to the untreated control cells $(\mathrm{P}<0.05)$. Taken together, these data suggest that PZH inhibits Caco-2 cell proliferation in a dose- and time-dependent manner.

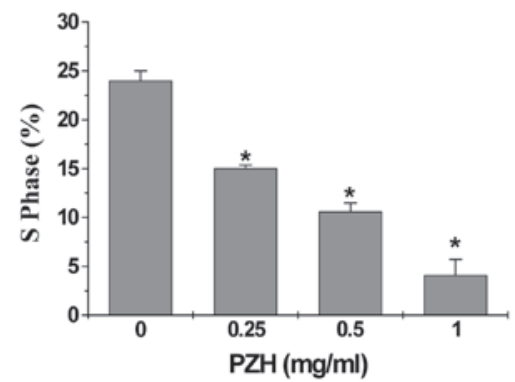

Figure 3. Effect of PZH on the cell cycle progression in Caco-2 cells. Cells were treated with the indicated concentrations of PZH for $24 \mathrm{~h}$, stained with PI, and analyzed by FACS. The proportion of DNA in the S-phase was calculated using ModfitLT version 3.0 Software. Data shown are averages with SD (error bars) from three independent experiments. " $\mathrm{P}<0.05$ vs. control cells.

A

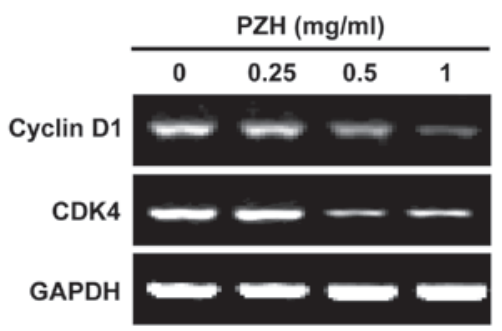

B

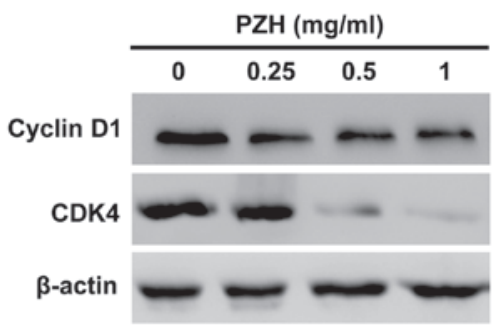

Figure 4. Effect of PZH on the expression of Cyclin D1 and CDK4 in Caco-2 cells. Cells were treated with the indicated concentrations of PZH for $24 \mathrm{~h}$. (A) The mRNA levels of Cyclin D1 and CDK4 in PZH-treated and untreated cells were determined by RT-PCR. (B) The protein expression levels of Cyclin D1 and CDK4 were analyzed by western blotting. GAPDH and $\beta$-actin were used as the internal controls for the RT-PCR or western blotting assays, respectively. Data are representative of three independent experiments.

PZH blocks G1/S progression of Caco-2 cells. The effect of $\mathrm{PZH}$ on the G1 to S progression in Caco-2 cells by PI staining, followed by FACS analysis. Subsequent to treatment with $0,0.25,0.5$ and $1 \mathrm{mg} / \mathrm{ml}$ of PZH the percentage of S-phase cells was found to be $24.0,15.0,10.59$ and $4.11 \%$, respectively $(\mathrm{P}<0.05)$ (Fig. 3), indicating that the inhibitory effect of PZH on Caco-2 cell proliferation is correlated with the arrest of G1/S cell cycle progression.

$P Z H$ regulates the expression of Cyclin DI and CDK4 in Caco-2 cells. To explore the mechanism of the anti-proliferative activity of $\mathrm{PZH}$, we performed RT-PCR and western blotting to respectively examine the mRNA and protein expression of Cyclin D1 and CDK4 in Caco-2 cells. As shown in Fig. 4, PZH treatment profoundly and dose-dependently reduced the expression of Cyclin D1 and CDK4, at both the transcriptional and translational levels. 


\section{Discussion}

Drug resistance and toxicity against normal cells limit the effectiveness of current cancer chemotherapies, including those used to treat colorectal cancer (3-5), emphasizing the need for the development of novel cancer chemotherapies. Natural products have received a lot of attention due to their relatively few side-effects compared to modern chemotherapeutics and have been used clinically for thousands of years as important alternative remedies for various diseases, including cancer (6,7). PZH a well-known traditional Chinese formula, first prescribed 450 years ago in the Ming Dynasty, has long been used in China for cancer treatment (22-24). Although it has been shown that PZH inhibits colon cancer growth via the induction of apoptosis and inhibition of tumor angiogenesis (26-28), the precise mechanism of its anticancer effect remains largely unclear. Therefore, in order for PZH to be developed further as an anticancer agent, its underlying molecular mechanism of action should be elucidated.

Cancer cells are characterized by an uncontrolled proliferation (15). Therefore, inhibiting excessive proliferation of tumor cells is one of the key approaches for the development of anticancer drugs. Using MTT and colony formation analyses, we demonstrated that $\mathrm{PZH}$ inhibited the proliferation of human colon carcinoma Caco- 2 cells, in a dose- and time-dependent manner. Eukaryotic cell proliferation is primarily regulated by the cell cycle. G1/S transition is one of the two main checkpoints of the cell cycle, responsible for initiation and completion of DNA replication (16). By using FACS analysis with PI staining, we found that PZH dosedependently repressed the G1 to $\mathrm{S}$ transition in Caco- 2 cells. G1/S progression is tightly regulated by the pro-proliferative Cyclin D1 and CDK4 (17). Overexpression of Cyclin D1 and CDK4 is commonly detected in various types of cancer (18-21). Consistent with the inhibitory effect of PZH on G1/S transition, our data indicated that $\mathrm{PZH}$ treatment suppressed the mRNA and protein expression of Cyclin D1 and CDK4 in Caco- 2 cells. In conclusion, the present study has demonstrated for the first time that $\mathrm{PZH}$ inhibited cancer cell proliferation by blocking $\mathrm{G} 1$ to $\mathrm{S}$ progression, which may be one of the mechanisms mediating its antitumor activity.

\section{Acknowledgements}

This study was sponsored by the National Natural Science Foundation of China (no. 81073097), the Developmental Fund of Chen Keji Integrative Medicine (no. CKJ 2011001), and the China Postdoctoral Science Foundation (no. 2012M511437).

\section{References}

1. Jemal A, Bray F, Center MM, Ferlay J, Ward E and Forman D: Global cancer statistics. CA Cancer J Clin 61: 69-90, 2011.

2. Gustin DM and Brenner DE: Chemoprevention of colon cancer: current status and future prospects. Cancer Metast Rev 21: 323-348, 2002.

3. Longley DB, Allen WL and Johnston PG: Drug resistance, predictive markers and pharmacogenomics in colorectal cancer. Biochim Biophys Acta 1766: 184-196, 2006.

4. Sun Y, Zhao H, Guo Y, Lin F, Tang L and Yao Y: Clinical study of combining chemotherapy of oxaliplatin or 5-fluorouracil/ leucovorin with hydroxycamptothecine for advanced colorectal cancer. Clin Oncol Cancer Res 6: 117-123, 2009.
5. Boose G and Stopper H: Genotoxicity of several clinically used topoisomerase II inhibitors. Toxicol Lett 116: 7-16, 2000.

6. Newman DJ, Cragg GM and Snader KM: The influence of natural products upon drug discovery. Nat Prod Rep 17: 215-234, 2000.

7. Gordaliza M: Natural products as leads to anticancer drugs. Clin Transl Oncol 9: 767-776, 2007.

8. Lin JM, Chen YQ, Wei LH, Chen XZ, Xu W, Hong ZF, Sferra TJ and Peng J: Hedyotis Diffusa Willd extract induces apoptosis via activation of the mitochondrion-dependent pathway in human colon carcinoma cells. Int J Oncol 37: 1331-1338, 2010.

9. Peng J, Chen YQ, Lin JM, Zhuang QC, Xu W, Hong ZF and Sferra TJ: Patrinia scabiosaefolia extract suppresses proliferation and promotes apoptosis by inhibiting STAT3 pathway in human multiple myeloma cells. Mol Med Rep 4: 313-318, 2011.

10. Lin JM, Wei LH, Xu W, Hong ZF, Liu XX and Peng J: Effect of Hedyotis Diffusa Willd extract on tumor angiogenesis. Mol Med Rep 4: 1283-1288, 2011.

11. Cai QY, Lin JM, Wei LH, Zhang L, Wang LL, Zhan YZ,Zeng JW, $\mathrm{Xu}$ W, Shen AL, Hong ZF and Peng J: Hedyotis diffusa Willd inhibits colorectal cancer growth in vivo via inhibition of STAT3 signaling pathway. Int J Mol Sci 13: 6117-6128, 2012.

12. Wei LH, Chen YQ, Lin JM, Zhao JY, Chen XZ, Xu W, LiuXX, Sferra TJ and Peng J: Scutellaria Barbata D. Don induces apoptosis of human colon carcinoma cell via activation of the mitochondriondependent pathway. J Med Plants Res 5: 1962-1970, 2011.

13. Wei LH, Lin JM, Xu W, Hong ZF, Liu XX, Sferra TJ and Peng J: Inhibition of tumor angiogenesis by Scutellaria Barbata D. Don via suppressing proliferation, migration and tube formation of endothelial cells and downregulation of the expression of VEGF-A in cancer cells. J Med Plants Res 5: 3260-3268, 2011.

14. Zheng LP, Chen YQ, Lin W, Zhuang QC, Chen XZ, Xu W, Liu XX, Peng J and Sferra TJ: Spica Prunellae extract promotes mitochondrion-dependent apoptosis in a human colon carcinoma cell line. Afr J Pharm Pharmacol 5: 327-335, 2011.

15. Evan GI and Vousden KH: Proliferation, cell cycle and apoptosis in cancer. Nature 411: 342-348, 2001.

16. Nurse P: Ordering $S$ phase and $M$ phase in the cell cycle. Cell 79: 547-550, 1994 .

17. Morgan DO: Principles of CDK regulation. Nature 374: 131-134, 1995 .

18. Harakeh S, Abu-El-Ardat K, Diab-Assaf M, Niedzwiecki A, El-Sabban M and Rath M: Epigallocatechin-3-gallate induces apoptosis and cell cycle arrest in HTLV-1-positive and-negative leukemia cells. Med Oncol 25: 30-39, 2008.

19. Kessel D and Luo Y: Cells in cryptophycin-induced cell-cycle arrest are susceptible to apoptosis. Cancer Lett 151: 25-29, 2000.

20. Purohit A, Hejaz HAM, Walden L, MacCarthy-Morrogh L, Packham G, Potter BVL and Reed MJ: The effect of 2-methoxyoestrone-3-O-sulphamate on the growth of breast cancer cells and induced mammary tumours. Int J Cancer 85: 584-589, 2000.

21. Zafonte BT, Hulit J, Amanatullah DF, Albanese C, Wang C, Rosen E, Reutens A, Sparano JA, Lisanti MP and Pestell RG: Cell-cycle dysregulation in breast cancer: breast cancer therapies targeting the cell cycle. Front Biosci 5: D938-D961, 2000.

22. Chinese Pharmacopoeia Commission (ed.). In: Pharmacopoeia of the People's Republic of China. Vol 1. Chinese Medical Science and Technology Press, Beijing, pp573-575, 2010.

23. Xu YY and Yu EX: Clinical analysis of the effect of Pien Tze Huang in treatment of 42 patients with moderate or advanced liver cancer. Shanghai J Tradit Chin Med 12: 4-5, 1994.

24. Gu ZX: Therapeutical observation of advanced colon cancer. Chin Tradit Patent Med 15: 23, 1993.

25. Liu CS. Review of Pharmacology and clinical application of Pien Tze Huang. Med Pharm World 7: 64-66, 2006.

26. Lin JM, Wei LH, Chen YQ, Liu XX, Hong ZF, Sferra TJ and Peng J: Pien Tze Huang-induced apoptosis in human colon cancer HT-29 cells is associated with regulation of the Bcl-2 family and activation of caspase 3. Chin J Integr Med 17: 685-690, 2011.

27. Zhuang QC, Hong F, Shen AL, Zheng LP, Zeng JW, Lin W, Chen YQ, Sferra TJ, Hong ZF and Peng J: Pien Tze Huang inhibits tumor cell proliferation and promotes apoptosis via suppressing the STAT3 pathway in colorectal cancer mouse. Int J Oncol 40: 1569-1574, 2012.

28. Shen AL, Hong F, Liu LY, Lin JM, Zhuang QC, Hong ZF, Sferra TJ and Peng J: Effects of Pien Tze Huang on angiogenesis in vivo and in vitro. Chin J Integr Med 18: 431-436, 2012. 